\section{Feasibility study: honey for treatment of cough in children}

\author{
Naveed Ahmed, 1 Alastair Sutcliffe, ${ }^{2}$ \\ Claire Tipper2
}

1Univeristy College London Medical

School, London; ${ }^{2}$ General and Adolescent Paediatric Unit, Institute of Child Health, University College London, UK

\section{Abstract}

Respiratory tract infections are an important health problem because of high incidence and economic costs. The World Health Organization identifies honey as a potential demulcent treatment for cough. The aim of this study is to determine: i) patient public perceptions towards a proposed randomized controlled trial (RCT) comparing the effects of honey to placebo for treatment of cough in children; ii) potential participation rates for proposed trial; iii) whether age and gender of parent or child impacts on proposed cough assessment tools. Forty adult participants with children age 1-6 years presenting with an upper respiratory tract infection were enrolled. They underwent a structured interview regarding the proposed trial and assessed their child's cough using two validated questionnaires. Eighty-eight percent of those recruited were willing to participate in the proposed trial. The two independently validated cough scores correlated well. A relationship between age and gender of child or parent with cough assessment score was not found. We conclude that a RCT to determine the effects of honey versus placebo is feasible. The public find the outcome measures and trial design acceptable.

\section{Introduction}

\section{Overview}

Coughing is a protective reflex action triggered by irritation or obstruction of the airways. Excess secretions and foreign bodies are cleared from the lungs by a combination of coughing and the mucociliary escalator. ${ }^{1}$ Physiologically a cough is a forced expiration against a closed glottis. ${ }^{2}$

All children experience coughs and community based surveys show that parental reported cough as an isolated symptom has a high prevalence. ${ }^{3}$ Cough has an impact on a child's ability to sleep, play and eat. It may disturb other family members' sleep and be disruptive at school. Acute coughs, usually caused by a viral upper respiratory tract infection (URTI), are self-limiting whereas chronic coughs are defined as those lasting longer than 8 weeks. ${ }^{4}$ Symptomatic URTI occurs in school age children on average 7-10 times a year. ${ }^{2}$

Cough constitutes 12 million GP visits per year, the largest single cause of primary care consultation, however, present UK general practice guidelines advise no treatment should be given. ${ }^{2}$ The mean cost per episode to the NHS is $£ 27.43$, to the parent $£ 14.77$ and annually to the NHS at least $£ 31.5 .5$

\section{Current treatment}

Over the counter cough medicines include combinations of antihistamines, decongestants, antitussives and expectorants. Systematic reviews show no evidence these products are of benefit compared to placebo. ${ }^{67}$ Despite this the UK market for these products in 2009 was worth $£ 437.2$ million. 8,9

There have been multiple reports of adverse effects associated with cough medicines. In children under 6 years of age decongestants have been linked to cardiac arrhythmias, antihistamines to hallucinations, and antitussives to depressed levels of consciousness and encephalopathy. ${ }^{7}$ Hospital episode statistics for England 2006/7 showed 230 children under 14 were admitted to hospital as a consequence of exposure to antitussives, expectorants or common cold remedies (11 poisoning by antitussives, 39 poisoning by expectorants, 182 poisoning by common cold remedies). ${ }^{10}$ The USA the Food and Drug administration identified 123 deaths related to the use of such products. ${ }^{7}$

The Medicines and Healthcare products Regulatory Agency (MHRA) now advises children less than 6 years old should not be treated with over the counter cough and cold medication. ${ }^{11}$ Carers have been advised that children suffering from cough should be treated with a simple cough syrup (such as glycerol, honey or lemon).

\section{Honey}

The World Health Organization regards honey as a potentially valuable demulcent for the treatment of cough. ${ }^{12}$ Honey is a sweet viscous liquid with a complex chemical composition of carbohydrates, free amino acids, vitamins, trace elements and flavonoids. It also contains compounds that function as antioxidants. It is said to possess anti-bacterial, antiviral and anti-inflammatory properties. ${ }^{13,14}$

Studies of the antimicrobial effect of honey have demonstrated its broad-spectrum antimicrobial actions against various gram-positive and gram-negative bacteria. It is also active against common bacteria found in the upper respiratory tract such as Staphylococcus aureus and Streptococcus faecalis, amongst others. ${ }^{14}$ Honey has been used in traditional medicine for the treatment of cough and is used in modern medicine to treat wounds and
Correspondence: Claire Tipper, General and Adolescent Paediatric Unit, Institute of Child Health, University College London, 30 Guilford Street, London, WC1N 1EH, UK.

Tel. +44.207.905.2190 - Fax: +44.207.905.2834

E-mail: c.tipper@ucl.ac.uk

Key words: upper respiratory infections, common cold, pediatrics, primary care, community medicine, common illnesses.

Acknowledgements: the authors would like to thank Green Light Pharmacy in Euston for their participation in this study. Ethical approval was obtained from UCL ethics committee Alpha.

Contributions: NA, data collecting, analyzing and manuscript writing; AS, manuscript reviewing. $\mathrm{CT}$, manuscript writing.

Conflict of interests: the authors declare no potential conflict of interests.

Received for publication: 5 March 2013.

Accepted for publication: 2 April 2013.

This work is licensed under a Creative Commons Attribution NonCommercial 3.0 License (CC BYNC 3.0).

(C)Copyright N. Ahmed et al., 2013

Licensee PAGEPress, Italy

Pediatric Reports 2013; 5:e8

doi:10.4081/pr.2013.e8

aid healing processes. ${ }^{15}$ The use of honey is prohibited under the age of one due to poor immunity against Clostridium Botulinum, a potential contaminant. 16,17

A review by Eccles, argues that the sweetness of liquid preparations used to treat cough accounts for much of the observed effect. ${ }^{18}$ The hypothesis suggests sweet substances naturally cause reflex salivation and production of airway mucus leading to a demulcent effect on the pharynx and larynx, thereby reducing cough. It is suggested that there is interaction between opioid-responsive sensory fibers and the gustatory nerves to help produce an antitussive effect via the central nervous system. ${ }^{18}$

\section{Assessment of cough}

Two validated measures of cough severity have recently been developed. The Canadian Acute Respiratory Illness and Flu Scale (CARIFS) is composed of 18 items covering three domains; symptoms (e.g. cough), function (e.g. ability of child to play) and parental impact (e.g. clinginess). ${ }^{19} \mathrm{~A}$ validated Pediatric cough questionnaire with a 7 point Likert Scale has also been developed by Paul et al. ${ }^{20}$

\section{Purpose of study}

This paper describes a feasibility study for a 
randomized controlled trial regarding the role of honey for the symptomatic relief of cough in children with self-limiting upper respiratory tract infections. Further to this we plan to conduct a pilot study to determine whether the proposed methods and instruments are appropriate and identify any potential practical difficulties with a larger study. ${ }^{8}$

\section{Objectives}

The principal objective is to determine public perception towards the proposed trial design and intervention as well as acceptability to families.

The secondary objectives are to estimate potential participation rates and to determine whether there is any correlation between the cough assessment questionnaire results and age or gender of parent or child.

\section{Materials and Methods}

An interview and questionnaire based study was used to determine the feasibility of a randomized controlled trial. The setting was a branch of the Green Light Pharmacy in Euston, a prominent community pharmacy. The inclusion criteria were; parents of children between the ages of one and six years presenting with cough as part of an URTI to the community pharmacy. Exclusion criteria were underlying respiratory illnesses, at the pharmacist's discretion.

\section{Consent}

The pharmacist introduced the parent to the student conducting the survey. The student discussed the information sheet and obtained written informed consent.

\section{Interview}

After consent had been obtained the student conducted a 15 question interview with the participant. This included questions regarding awareness of alternative cough treatments (including honey), use of over the counter medicines and willingness to participate in a proposed future trial.

\section{Cough assessment}

The participant was asked to fill in two validated questionnaires to assess their child's cough. The 5 domain validated questionnaire was chosen as it was used in the only published randomized controlled trial investigating the effect of honey on cough in young children to date. ${ }^{20}$ The 18 item CARIFS is a valid measure of functional severity and burden of illness to the parent. ${ }^{14}$ Using both questionnaires maximized our ability to assess cough severity and its impact on both the child and parent. The raw data was entered into
Microsoft Excel verbatim and coding was applied to allow the data to be analyzed in SPSS. The data was normalized to compare questionnaires.

\section{Results}

Forty adult participants were enrolled in the study, mean age 32 (range: 22-55). The mean age of the children was 3 years (range 1-6 years). The results showed $88 \%$ of participants would be willing to take part in the proposed trial (Figure 1); 39 of the 40 participants were content to use honey to treat their child's cough. On questioning only $65 \%$ were willing to fill in a diary continuously for a five day period.

The scores generated by the participants on both the CARIF and the Paul et al. questionnaire are shown in Figure 2. There was a strong positive correlation between the questionnaires (Figure 3 ) and using SPSS, a significant $(\mathrm{P}<0.01)$ Pearson product moment correlation coefficient was calculated (0.66).

A Bland-Altman plot was constructed to ana-

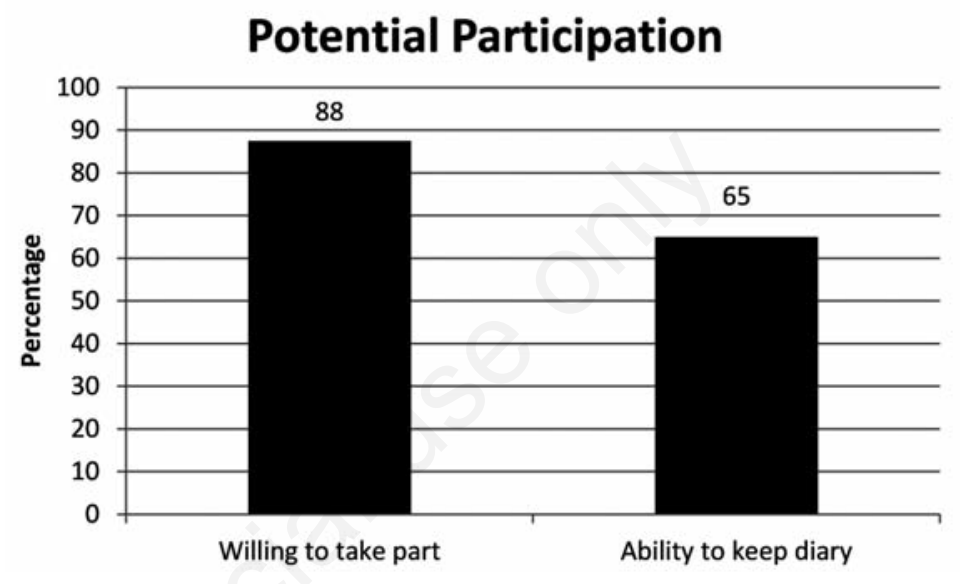

Figure 1. Participation rates for the proposed Randomized Controlled Trial.

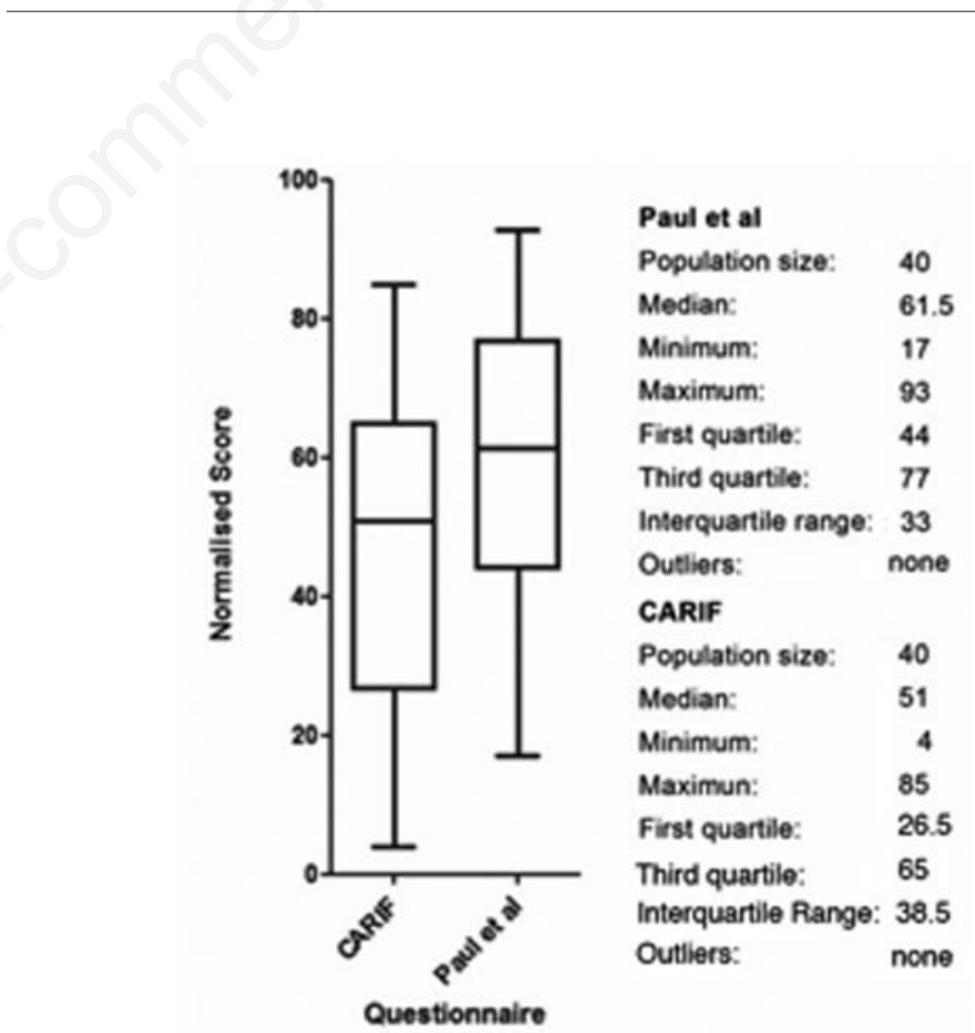

Figure 2. A comparison between the scores obtained on the Canadian Acute Respiratory Illness and Flu Scale and Paul et al. questionnaire. The data has been normalized. 
lyze agreement between the two different variables (Figure 4). This showed an acceptable correlation of 0.46 .

The results from the cough assessment questionnaire were comparable to the initial trial used to validate the CARIF questionnaire. The mean score for the CARIF validating trial was 27.99 (95\% CI: 38.25-17.73). Our sample of data had a mean of 25.35 ( $95 \%$ CI: 38.27-12.43). The overlapping confidence intervals show that the participants in this trial were comparable to those used in the validation trial.

There was no correlation between the gender or age of parent or child with the total score for either CARIF or Paul et al. (Table 1). If there was such a correlation this would question the validity.

A t test was used to compare the parent's gender $(\mathrm{P}=0.91)$ and the child's gender $(\mathrm{P}=0.344)$ with the final score in the cough assessment questionnaire. The confidence intervals overlapped confirming no statistically significant difference in cough assessment.

To further support this a linear regression model was also used to determine whether there was a relationship between the gender of an individual assessing their child and the final score in each of the questionnaires. The confidence intervals for male and female overlapped for both CARIF and Paul et al. therefore no significant difference was seen. There was therefore no relationship between the parents' gender and total scores on either questionnaire.

\section{Discussion}

Cough caused by URTI can be a troubling symptom for both children and their parents, who are often keen for treatment. However, a systematic review conducted by Schroeder et al., in 2004 shows that there is little evidence for the effectiveness of over the counter cough medicines. 6 The NHS encourages self-medication for acute self-limiting illnesses and the World Health Organization has recommended honey for its topical demulcent effect in treating cough. 12

This study demonstrates that the public would be willing to participate in a trial investigating the effects of honey in comparison to placebo for the treatment of cough in children. The measures that we propose to use are acceptable to the public and the figures for potential recruitment are high.

This feasibility study involved 40 participants. One reason for the small sample size is that the study was conducted from January onwards. Ideally, the main trial would start in November to maximize potential recruitment rates as the highest incidence of upper respi ratory tract infections are between October and February. We propose to follow this feasi-

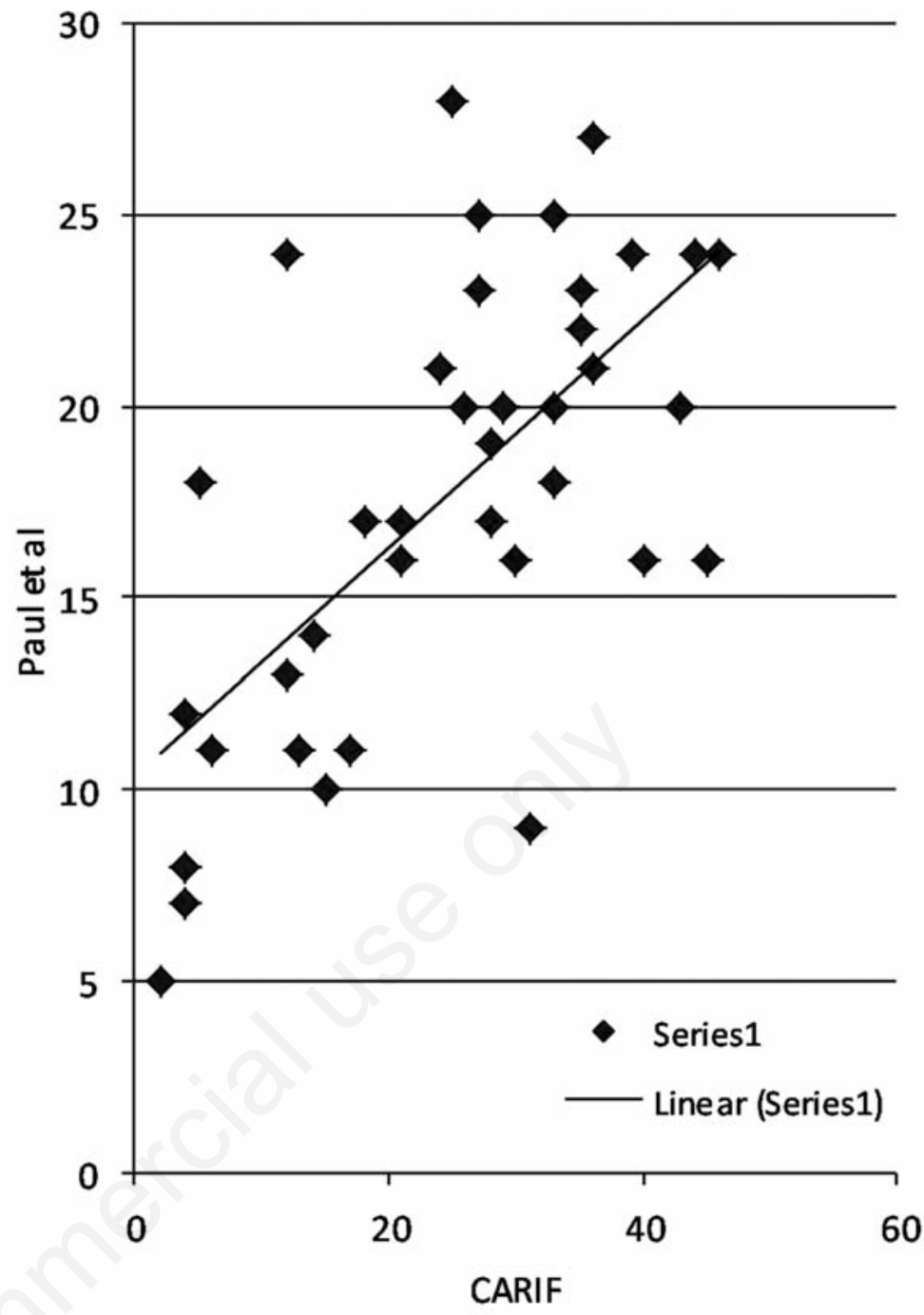

Figure 3. Scatter graph comparison of the Canadian Acute Respiratory Illness and Flu Scale with Paul et al.

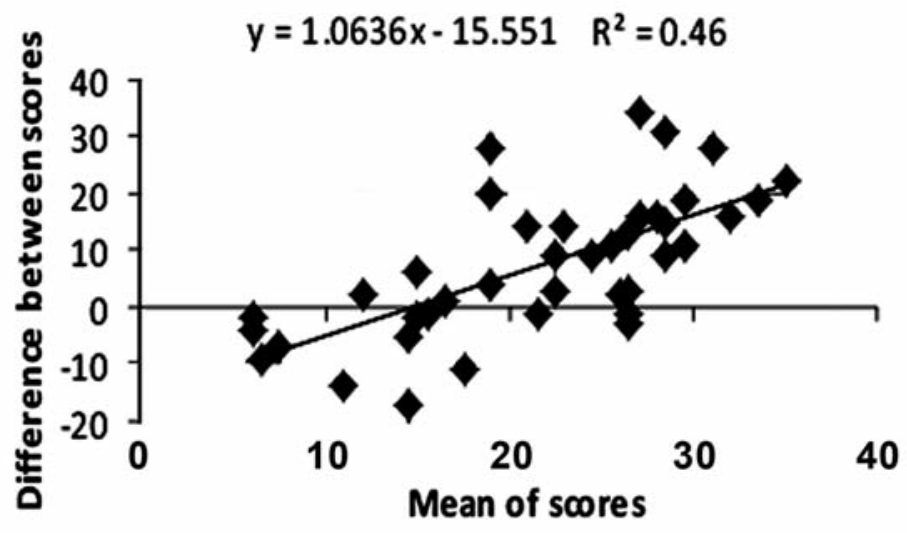

- Series1 - Linear (Series1)

Figure 4. Bland Altman plot for Canadian Acute Respiratory Illness and Flu Scale and Paul et al. questionnaire. 
Table 1. Results of Pearson correlation coefficient and its significance. Cough score results analyzed for differences depending on age or gender of child and parent.

\begin{tabular}{lcccc} 
& \multicolumn{2}{c}{ CARIF } & \multicolumn{2}{c}{ Paul et al. } \\
& Correlation & Significance & Correlation & Significance \\
Participant gender & 0.120 & 0.460 & 0.018 & 0.911 \\
Participant age & 0.314 & 0.052 & -0.002 & 0.989 \\
\hline Child's gender & -0.300 & 0.852 & -0.153 & 0.345 \\
Child's age & -0.330 & 0.841 & -0.310 & 0.850 \\
\hline
\end{tabular}

bility study with a pilot trial where 270 individuals will be randomized to honey or placebo.

\section{Interview}

On questioning the potential participation rate for the trial was $88 \%$ but only $65 \%$ were willing to fill in a diary continuously for a five day period. Participants initially felt filling out the questionnaires would be too time consuming, especially if parents had other children to look after or were working. However, after completing the questionnaire and realizing the short amount of time required, parents were then willing to reconsider. This observation was not reflected in the results and therefore the percentage of people willing to keep a diary is likely to be higher. The questionnaire currently excludes non English speakers. Fortunately the area that we conducted the study was inhabited by a large Bangladeshi and Pakistani population with whom the student was able to communicate. Some people were excluded due to language difficulties which may be overcome by using translated questionnaires.

\section{Cough assessment}

The results from the cough assessment questionnaire were comparable to the initial trial used to validate the CARIF questionnaire.

\section{Results}

There was no statistically significant relationship when comparing the age or gender of the parent to the total score when assessing their child's cough. Similarly the gender of the child had no effect on the assessment of the child's cough.

\section{Future work}

The next stage of the trial is to conduct a pilot study. We propose a double blind randomized controlled trial comparing honey with placebo during the winter season. This will allow us to refine our methodology and calculate the adequate sample size required for a full study.

\section{Conclusions}

In conclusion, this feasibility study is a valuable indicator for the potential success of a proposed future randomized controlled trial. The data collected corresponds well with previous trials in the field and the outcome measures proposed in the study are acceptable to the public. The questionnaires were filled in without difficulty by English speakers and there was a general positive attitude towards the trial. Age and gender of parent or child did not appear to affect cough assessment which was reassuring.

\section{References}

1. Rutter P. Community pharmacy: symptoms, diagnosis and treatment. 2nd ed. Churchill Livingstone; 2009.

2. Morice AH, McGarvey L, Pavord I. Recommendations for the management of cough in adults. Thorax 2006;61 Suppl 1:i1-24.

3. Ninan TK, Macdonald L, Russell G. Persistent nocturnal cough in childhood: a population based study. Arch Dis Child 1995;73:403-7.

4. Morice AH. Epidemiology of cough. Pulm Pharmacol Ther 2002;15:253-9.

5. Hollinghurst S, Gorst C, Fahey T, Hay AD. Measuring the financial burden of acute cough in pre-school children: a cost of illness study. BMC Fam Pract 2008;9:10

6. Schroeder K, Fahey T. Over-the-counter medications for acute cough in children and adults in ambulatory settings. Cochrane Database Syst Rev 2004: CD001831.

7. Sharfstein JM, North M, Serwint JR. Over the counter but no longer under the radar-pediatric cough and cold medications. $\mathrm{N}$
Engl J Med 2007;357:2321-4.

8. Evans H, Tuleu C, Sutcliffe A. Is honey a well-evidenced alternative to over-thecounter cough medicines? J R Soc Med 2010;103:164-5.

9. PAGB. The Proprietary association of Great Britain annual review and report 2010. London: The Proprietary Association of Great Britain; 2010.

10. MHRA. Overview: risk benefit of cough and cold medicines in children. Available from: http://www.mhra.gov.uk/home/groups/plp/documents/websiteresources/con041374 .pdf.

11. MHRA. Drug safety update 2009. Available from: http//www.mhra.gov.uk/home/groups/ pl-p/documents/publication/con043810.pdf.

12. WHO. Cough and cold remedies for the treatment of acute respiratory infections in young children 2001. Geneva: World Health Organization; 2001.

13. Sanz ML, Gonzalez M, de Lorenzo C, et al. Carbohydrate composition and physico chemical properties of artisanal honeys from Madrid (Spain): occurrence of Echium sp honey. J Sci Food Agric 2004;84: 1577-84.

14. Mullai V, Menon T. Bactericidal activity of different types of honey against clinical and environmental isolates of pseudomonas aeruginosa. J Altern Complement Med 2007;13:439-41.

15. Simon A, Traynor K, Santos K, et al. Medical honey for wound care - still the latest resort? Evid Based Complement Alternat Med 2009;6:165-73.

16. Kuplulu 0, Goncuoglu M, Ozdemir H, et al. Incidence of Clostridium botulinum spores in honey in Turkey. Food Control 2006;17:222-4.

17. Nevas M, Hielm S, Lindstrom M, et al. High prevalence of Clostridium botulinum types $A$ and $B$ in honey samples detected by polymerase chain reaction. Int $\mathrm{J}$ Food Microbiol 2002;72:45-52.

18. Eccles R. Mechanisms of the placebo effect of sweet cough syrups. Respir Physiol Neurobiol 2006;152:340-8.

19. Jacobs B, Young NL, Dick PT, et al. Canadian acute respiratory illness and flu scale (CARIFS): Development of a valid measure for childhood respiratory infections. J Clin Epidemiol 2000;53:793-9.

20. Paul IM, Beiler J, McMonagle A, et al. Effect of honey, dextromethorphan, and no treatment on nocturnal cough and sleep quality for coughing children and their parents. Arch Pediatr Adolesc Med 2007; 161:1140-6. 